\title{
Evaluering van 'n opleidingskursus in bestuursbeginsels en -tegnieke vir eerstelyntoesighouers by 'n Suid-Afrikaanse landboukoöperasie
}

\author{
Willie Strydom* \\ Sentraalwes (Kooperatich) Beperk, Posbus 31, Klerksdorp 2570, Republiek van Suid-Afrika
}

Alret Barnard

Departement Bedryf- en Personeelsielkunde, Potchefstroomse Universiteil vir C.H.O.. Potchefstroom 2520, Republiek van Suid-Afrika

Onlvang Junie 1993, aanvaar Oktober 1993

\begin{abstract}
Evaluation of a training course in management principles and techniques for first-line supervisors at a South African argricultural corporation. In this article the effect of a management course for first-line supervisors is evaluated in respect of their knowledge, attitudes and behavioural skills, as well as the effect of the course on their subordinates, by means of a three-group design, consisting of randomly selected persons in an experimental group and two control groups. Questionnaires were completed prior to commencement of the course, directly upon completion and again three months later, by the Experimental Group and Control Group One. Control Group Two was exposed to the measuring devices only after the post and post-post phases, to determine the effect of repeated testing. The original random selection includod 50 supervisors and 100 subordinates. At the post-post evaluation, however, those numbers had decreased to 25 and 43 respectively. Owing to the fact that the experimental and control groups were randomly selected from the population of first-line supervisors, hypotheses were tested with the help of inferential statistics as well as $\mathrm{t}$ - and p-values. In terms of knowledge and attitude the tests indicated that the supervisors in the Experimental Group performed significantly better than those in Control Group One, not only after completion of the course, but also three months later. The behavinural patterns of supervisors in the Experimental Group, and therefore the effect thereof on the attitude of their subordinates, do not, however, differ significantly from those of supervisors and their subordinates in Control Group Onc. The external factors which may have detrimentally influenced the applicatory value should be further investigated in order to retain the concomitant and supportive behavioural skills. It is especially advised that further investigations be launched regarding the level of difficulty of the course, its applicatory value for higher levels of supervision, as well as the training officer's role in respect of facilitation thereof as an alternative training and developing intervention. especially with regard to improvement of behavioural patterns.
\end{abstract}

\begin{abstract}
Die doel van die artikel was om 'n bestuurskursus vir toesighouers te evalucer ten opsigte van hulle kennis, houdings en gedragsvaardighede, sowel as die effek van die kursus op hul ondergeskiktes se houdings. 'n Ewekansige driegroepontwerp bestaande uit ' $n$ eksperimentele groep en twee kontrolegroepe is gebruik. Deur middel van die tweede kontrolegroep is die effek van herhaalde toetsing bepaal. Die oorspronklike steckproef het bestaan uit 50 toesighouers en 100 ondergeskiktes wat ten tyde van die na-nameting na 25 en 43 respektiewelik verminder het. Daar is gevind dat dié kursus eerstelyntoesighouers se kennis en houdingsingesteldheid beduidend verbeter het. gemeet oor 'n driemaandeperiode. Geen beduidende verbetering is egter ten opsigte van gedragsvaardighede van toesighouers en houdingsingesteldheid by ondergeskiktes gemeet nie. Ter wille van dic behoud van die gepaardgaande en ondersteunende gedragsvaardighede behoort eksterne faktore, wat moontlik die kursus se toepassingswaarde negatief beïnvloed het, verder nagevors te word.
\end{abstract}

*Aan wie korrespondensie gerig moet word.

\section{Probleemstelling}

In 'n veranderende Suid-Afrika, met geweldige nuwe uitdagings, sal toekomstige sakebestuurders buitengewone leierskap en aanpasbaarheid aan dic dag moet lê, en ook 'n sensitiwitcit vir veranderde sosialc faktore moet ontwikkcl (Nortje \& Crous, 1990: 27). Dit is duidelik dat dic huidige asook gevisualiscerde sakeomgewing groot cise aan bestuurders gaan stel en in baic gevalle sclfs ' $n$ reoričntasic van bestuur sal vereis. Dic problcem ontstaan egter wanneer hierdie veranderinge tussen mens en omgewing nic gesinchroniscerd is nic. Lipman het reeds in 1914 na hicrdie wanbalans verwys en dit soos volg gestel: 'We have changed our environment more quickly than we know how to change ourselves' (Nortje \& Crous, 1990: 27).

Verouderde bestuursbeginsels en -tegnicke is dus 'n realiteit wat in die komende dckade en daama ernstig aangespreek sal moet word. Volgens Myburgh (1988: 1) en Strydom (1993: 3) word gevolglik al groter druk op oplcidingsdepartemente geplaas on docltreffend, binne 'n koste-effcktiewe raamwerk, met opleidingsbchocftes tred te hou. Orga- nisasies kan dit dus nic bekostig om hoop-dit-tref-opleiding aan te bied nie sonder die evaluering van die opleidingsbehocftes nie. Evalucring is 'n effekticwe manier om opleidingskursusse se sukses te bepaal. Indien ' $n$ kursus se insette met dic kursus se uitsette (sukses) vergelyk word, kan die koste-effektiwiteit van so 'n kursus in 'n groot mate bepaal word (Deterline, 1977: 14). Ongclukkig neig die meeste opIcidingsdepartemente steeds om hul fondse eerder aan opleidingspakkctte en kursusaanbicding as aan die evaluering van kursusse tc bestce (Bell \& Kerr, 1987: 70). 'n Rede hiervoor, volgens Marais \& Vlok (1981: ongenommer), is dat instrukteurs glo dat dit onmoontlik of te moeilik is om kognitiewe of bestuursvaardighede soos motivering en kommunikasie as studiconderwerp te evalueer. Dit is ongetwyfeld aansienlik makliker om die prestasie van tegniese werkers te meet na 'n opleidingsessie wat 'n verbetering in tegniese werk as doclstelling gehad het, as die prestasie van ' $n$ toesighouer wat ' $n$ opleidingsessic oor menslike verhoudings 
bygewoon het. Derhalwe word evaluering van bestuurskursusse dikwels as problematics beskou en gevolglik afgeskeep (Basson, 1987: 70), indien dit hocgenaamd aangepak word (Bimbrauer, 1987: 53).

Ter beklemtoning van die dringendheid om wel gecivalueerde bestuurskursusse aan te bied, wys Norijé \& Crous (1990: 2) daarop dat toesighoucrs in Suider-Afrika midde-in 'n golf van verandering, wat ongekend in dic geskiedenis van die land is, staan en dat alles daarop dui dat hierdie verandering teen die einde van hicrdic eeu slegs groter momentum sal kry.

Wat dic veranderingtendense egter ook al mag behels, mag dit nie toesighouers in hul bestuur belemmer nic. Toesighouers moet dus opgelei word om te kan voldoen aan die al groter wordende uildagings en hoèr verwagtings. Dit is veral belangrik dat dic praktiese tocpassing van bestuursvaardighede, asook dic effek wat dit op ondergeskiktes het, buiten konvensionele opleiding, al hoe meer aandag behoor te genict.

Dic betrokke landboukoöpcrasic waar dic navorsing wat hicr gerapporteer word, gedoen is, het in die laat tagtigerjare 'n bestuurskursus aan die hand van erkende bestuursbeginsels en -tegnicke ontwikkel. Hierdie beginsels en tegnicke sluit onder andere lecrdoelwitte soos leicrskapsvaardighede, die daarstel van ' $n$ program en skedulc, organiscring van beplande aksies, leiding en beheer in. Omdat die koöperasie oor 'n groot aantal sekondêr-geskoolde toesighouers beskik, was die kursus vir dic koöperasie van kardinale belang. Onopgeleide toesighouers leer dikwels negaticwe gedrag aan wat moeilik verander kan word en dit is derhalwe belangrik dat toesighouers die vaardighede van toesighouding moet aanleer voordat hulle aan tocsighoudende situasics blootgestel word (Jacobs, 1985: 35).

Volgens Heunis (1981: 67-72) is dit egter ook belangrik dat oplcidingsbeamptes moet toesien dat geld en tyd wel op oplcidingsbehoeftes geinvesteer word en dat daar nie sonder die nodige evalucring enige lukrake opleidings- of ontwikkelingsintervensies geloods word nic. Flippo (1981: 207) ondersteun hicrdic gedagte as hy noem dat dic enigste antwoord op dic evaluering van bestuurskursusse slegs in die wetenskaplike beoordeling van opleidingsresultatc lê.

Die docl van hicrdie artikcl was dan ook om op ' $n$ wetenskaplik-gefundecrde basis genœemde bestuurskursus vir eerstelyntoesighouers te evalueer ten opsigte van hulle kennis, houdings en vaardighede, sowel as dic effek daarvan op ondergeskiktes se houdings, ten einde die doelureffendheid daarvan vir dic betrokke landboukooperasie te bepaal.

\section{Hipoteses}

Die volgende hipoteses word gestel na aanleiding van die probleem- en doclstellings:

H1: Daar is 'n statisties beduidende verskil in die kennis van ecrstelyntocsighouers voor en dirck na dic bywoning van die bestuurskursus, vergeleke met eerstelyntoesighouers wat nic dic kursus deurloop het nie.

H2: Daar is 'n statisties beduidende verskil in dic houding van cerstelyntocsighouers voor en direk na dic bywoning van dic bestuurskursus, vergeleke met cerstelyntoesighouers wat nic dic kursus deurloop het nie.
H3: Daar is 'n statisties beduidende verskil in die vaardighede van eerstelyntoesighouers voor en direk na die bywoning van die bestuurskursus, vergeleke met eerstelyntoesighouers wat nie dic kursus deurloop het nie.

H4: Daar is 'n statisties beduidende verskil in die kennis van eerstelyntoesighouers voor en drie maande na die bywoning van die bestuurskursus, vergeleke met eerstelyntoesighouers wat nie die kursus deurloop het nie.

H5: Daar is 'n statisties beduidende verskil in die houding van eerstelyntoesighouers voor en drie maande na die bywoning van die bestuurskursus, vergeleke met eerstelyntoesighouers wat nic die kursus deurloop het nie.

H6: Daar is ' $n$ statisties beduidende verskil in die gedragsvaardighede van eerstelyntoesighouers voor en drie maande na dic bywoning van die bestuurskursus, vergeleke met cerstelyntoesighouers wat nie die kursus deurloop het nie.

H7: Daar is 'n statisties beduidende verskil ten opsigte van die ondergeskiktes se houding (werkstevredenheid en werksgemotiveerdheid) voor en drie maande nadat die ondergeskiktes se ecrstclyntoesighouers die bestuurskursus deurloop het, vergeleke met die ondergeskiktes wie se cerstclyntoesighouers nic die kursus dcurbop het nie.

\section{Metode van ondersoek}

Die navorser het gebruik gemaak van 'n gekontroleerde veldeksperiment waarin 'n groep eerstelyntoesighouers opgelei is in bestuursbeginsels en -tegnicke. Daar is verder gcbruik gemaak van 'n ewekansige driegroepontwerp bestaande uit 'n eksperimentele groep en twee kontrolegroepe. Dic tweede kontrolegroep het dic moontlike effek van herhaaldc toctsing bepaal. Dic aanvanklike steekgroep het uit 50 toesighouers bestaan (Eksperimentele $n=20$, Kontrolegroep $1 n=20$ en Kontrolegroep $2 n=10$ ), getrek uit 'n populasic van 60 toesighouers en 100 ondergeskiktes uit 'n populasie van 150 . Onder kontrak word hierdie toesighouers, asook hul onder- en oorgeskiktes, ongelukkig van tyd tot tyd van een bedryfspunt na ' $n$ ander verskuif om diens aldaar te verrig - landboutoestande vereis dit en die betrokke landboukoßperasic (met oor die 100 bedryfspunte) het nie altyd oral ewe vecl werk nic. In die studie is 19 proefpersone (met hulle ondergeskiktes) ongelukkig as gevolg hiervan verminder en uitgeskakel, nie alleen wanneer die betrokke procfpersoon self van bedryfspunt moes verander nie, maar ook wanneer of sy oorgeskikte of beide sy ondergeskiktes (wat in die studie betrek is), moes skuif. Weens veranderinge in dic organisasiestruktuur, swak ekonomiese omstandighede, te hoð onkoste, persoonlike redes soos sickte en onvoorsiene werksomstandighede, kon 'n verdere ses persone egter uiteindelik ook nie die navorsing meemaak of voltooi nic. Die aantal toesighouers het ten tyde van die na-na-evalucring dric maande later dus verminder na 25 toesighouers (Eksperimentele $\mathbf{n}=9$; Kontrole groep $1 \mathrm{n}$ $=9$ en Kontrolegroep $2 n=7$ ) en 43 ondergeskiktes (Eksperimentcle $n=16$, Kontrolegroep $1 \mathrm{n}=19$ en Kontrolegroep $2 n=8$ ). Aangesien proefpersone uit al drie groepe hoofsaaklik slegs as gevolg van hulle onderskeie bedryfspunte se ligging uitgeval of verminder het, is aanvaar 
Tabel 1 Navorsingsontwerp

\begin{tabular}{|c|c|c|c|c|c|c|c|c|}
\hline $\mathbf{R}$ & M1 & $\rightarrow$ & $x$ & $\rightarrow$ & M2 & $\rightarrow$ & M3 & (Fkspcrimentele groep) \\
\hline $\mathbf{R}$ & M1 & 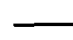 & & $\longrightarrow$ & M2 & $\rightarrow$ & M3 & (Kontrolegroep 1) \\
\hline $\mathbf{R}$ & & & & & M2 & $\rightarrow$ & M3 & (Kontrolegroep 2) \\
\hline
\end{tabular}

$$
\begin{aligned}
& \text { Simbole in die tabel stel die volgende voor: } \\
& \mathbf{R}=\text { ewekansig-geselckteerde groep } \\
& \text { M1 = voormeting/evaluering } \\
& \text { M2 = nameting/evaluering (dirck na kursus) } \\
& \text { M3 = na-na-meting/evalucring (na drie maande tydsverloop) } \\
& \text { X = bestuursopleidingsingreep (ses dae) }
\end{aligned}
$$

dat daar nie werklik verskille ten opsigte van faktore soos byvoorbeeld persoonlikheidscienskappe sou wees tussen dié proefpersone wat die eksperiment voltooi het en dié wat uitgeval het nie.

Die evaluering is voor, na en ook drie maande na afloop van die opleidingskursus gedoen om die blywende aard van veranderings in kennis, houdings en vaardighede te evalueer.

Grafies kan die navorsingsontwerp volgens Schilbach (1983: 641) soos volg voorgestel word (kyk na Tabel 1).

Dic meetinstrumente het bestaan uit:

-'n kursustoets wat gebruik is om sowel dic cksperimentcle as kontrolegrocpe se kennis van bestuursbeginsels in die voor, na en na-na-fases te evalucer.

- houdingsvraelyste (Likert-skaal) wat gebruik is om dic toesighouers se gesindheidsverandering teenoor die kursusinhoud asook die effek van die kursus op ondergeskiktes te evalueer. Elke item in die houdingsvraclyste is voor insluiting krities beoordecl aan die hand van die kriteria soos gestcl dcur Edwards (1957). Dit is ook vir gesigsgeldigheid getocts deur dit aan twee akademici voor te lê vir evalucring.

- 'n gedragsvaardigheidsvraelys wat deur die toesighouers se oorgeskiktes ingevul is betreffende die mate waarin die toesighouers die bestuursbeginsels toegepas het.

\section{Resultate}

\begin{tabular}{|c|c|c|c|c|c|c|}
\hline \multirow[b]{2}{*}{ Veranderlikes } & \multicolumn{2}{|c|}{$\begin{array}{l}\text { Eksperimentele } \\
\text { Groep }(n=16)\end{array}$} & \multicolumn{2}{|c|}{$\begin{array}{c}\text { Konlrolegroep } 1 \\
(n=19)\end{array}$} & \multirow[b]{2}{*}{ t-waarde } & \multirow[b]{2}{*}{ p-waard } \\
\hline & $x$ & $\mathbf{s}$ & $\bar{x}$ & 3 & & \\
\hline $\begin{array}{l}\text { Kennisvraelys } \\
\text { Houdings- }\end{array}$ & 57 & 9 & 59 & 7 & -0.6792 & 0.5058 \\
\hline $\begin{array}{l}\text { vraelys } \\
\text { Gedragsvaardig }\end{array}$ & 64 & 4 & 65 & 4 & -1.1925 & 0.2461 \\
\hline $\begin{array}{l}\text { hede } \\
\text { Houdingsvrae- } \\
\text { lys vir onder- }\end{array}$ & 64 & 20 & 54 & 16 & 1.3408 & 0.2000 \\
\hline geskiktes & 75 & 5 & 72 & 9 & 1.0824 & 0.2955 \\
\hline
\end{tabular}

Die resultate van dic eksperimentele en kontrolegroepe is deur middel van t-toetse met betrekking tot dic dric fases van evaluering vergelyk. Dis belangrik om daarop te let dat

Tabel 2 Verskille in gemiddeldes tussen die Eksperimentele Groep en Kontrolegroep 1 (voor toetsing) dic hieropvolgende tabelle se resultate in 'n persentasieskaal omgesit word (met 'n maksimum van 100 en 'n minimum van 0) om dic vergelyking tussen veranderlikes in perspektief te plaas. In Tabel 2 word die resultate van die totale

\begin{tabular}{|c|c|c|c|c|c|c|c|}
\hline $\begin{array}{l}\text { Verander- } \\
\text { likes }\end{array}$ & $\mathbf{N}$ & $\bar{x}$ & $\mathbf{s}$ & $t$ & $\mathbf{p}$ & $\begin{array}{c}\text { Effek- } \\
\text { grooule d }\end{array}$ & $\begin{array}{l}\text { Bonferroni } \\
\text { aanpassing }\end{array}$ \\
\hline Kl & 11 & 11 & 7 & 4.68 & $0.0009 *$ & $1.4110^{* *}$ & $0.0018^{*}$ \\
\hline HI & 11 & 6 & 6 & 3.60 & $0.0048 *$ & $1.0854 * *$ & $0.0096^{*}$ \\
\hline GI & 9 & 8 & 16 & 1.46 & 0.1826 & 0.4866 & \\
\hline $\mathrm{K} 2$ & 9 & 0 & 6 & -0.13 & 0.9001 & -0.0433 & \\
\hline $\mathrm{H} 2$ & 9 & 4 & 4 & 2.05 & 0.0741 & 0.6833 & \\
\hline G2 & 7 & 4 & 6 & 1.73 & 0.1344 & 0.6538 & \\
\hline $\mathrm{K} 3$ & 9 & 11 & 9 & 3.73 & $0.0058 *$ & $1.2433^{* *}$ & $0.0116^{*}$ \\
\hline H3 & 9 & 10 & 4 & 7.73 & $0.0001 *$ & $2.5766^{* *}$ & $0.0002^{*}$ \\
\hline G3 & 7 & 11 & 18 & 1.62 & 0.1569 & 0.6123 & \\
\hline $\mathrm{OH} 3$ & 14 & 5 & 4 & 1.65 & 0.1510 & 0.4409 & \\
\hline
\end{tabular}
groep ten opsigte van kennis, houdings en gedragsvaardig. hede vergelyk voordat dic kursus aan dic eksperimentele

Tabel 3 Beduidendheid van die verskiltellings van die Eksperimentele Groep ten opsigte van die verskillende veranderlikes

* = Statistics beduidend

** = Prakties beduidend

$X=$ Verskil in gemiddeldes

$\mathrm{K} 1$ = Gemiddelde verskil tussen die voor- en natellings vir kennisevaluering

$H 1$ = Gemiddelde verskil tussen dic voor-en natellings vir houdingsvraelyste

GI = Gemiddelde verskil tussen die voor- en natellings vir gedragsverandering

K2 = Gemiddelde verskil tussen die na- en na-na-tellings vir kennisevaluering

112 = Gemiddelde verskil tussen die na- en na-natellings vir houdingsvraelyste

G2 = Gemiddelde verskil tussen die na- en na-na-tellings vir gedragsveranderings

K3 = Gemiddelde verskil tussen die voor- en na-na-tellings vir kennisevaluering

113 = Gemiddelde verskil tussen die voor- en na-na-tellings vir houdingsvraelyste

G3 = Gemiddelde verskil tussen die voor-en na-na-tellings vir gedragsverandering

OH3 = Gemiddelde verskil tussen die voor- en na-na-tellings vir ondergeskiktes se houdingvraelyste 
groep aangebicd is.

In Tabel 2 word aangetoon dat daar geen statisties beduidende verskil tussen dic resultate van dic twee groepe voor die aanvang van dic kursus bestaan het nic. Die proefpersone het dus gelyk presteer ten opsigte van die veranderlikes wat getoets is.

In Tabel 3 word dic beduidendheid van die verskiltellings tussen dic gemiddeldes binne groepc, vir dic Eksperimentele Groep aangetoon.

As 'n p-waarde van $5 \%(0.05)$ as statisties beduidend geneem word, kan uit Tabel 3 afgelei word dat die kennis en houdingsingesteldheid van dic eerstelyntoesighouers beduidend verbeter het, ook na dic Bonferroni-aanpassing, vanweè dic kursusinset. Ten opsigte van die eerstelyntoesighouers se gedragsvaardighede en hul ondergeskiktes se houdingsingesteldheid blyk dit of die verskille in rekenkundige gemiddeldes oénskynlik positief is. Die verskille is

Tabel 4 Beduidendheid van die verskiltellings van Kontrolegroep 1 ten opsigte van die verskillende veranderlikes

\begin{tabular}{lrrrrr}
\hline Veranderlikes & $N$ & $\bar{x}$ & $s$ & t-wsarde & p-waarde \\
\hline K1 & 15 & -4 & 7.5 & -1.96 & 0.0699 \\
H1 & 15 & 2 & 5 & 1.28 & 0.2218 \\
G1 & 14 & 0 & 16 & 0.06 & 0.9493 \\
K2 & 11 & 1 & 3 & 0.96 & 0.3535 \\
H2 & 11 & -2 & 3 & -1.62 & 0.1273 \\
G2 & 7 & 1 & 14 & 0.27 & 0.7925 \\
K3 & 11 & -3 & 8 & -1.41 & 0.1797 \\
H3 & 11 & 0 & 4 & 0.05 & 0.9570 \\
G3 & 7 & 7 & 16 & 1.24 & 0.2516 \\
OH3 & 18 & 2 & 9 & 0.88 & 0.4095 \\
\hline
\end{tabular}

Tabel 5 Beduidendheid van die verskiltellings (na- en na-na-tellings) van Kontrolegroep 2 ten opsigte van die verskillende veranderlikes

\begin{tabular}{lrrrrr}
\hline Veranderlikes & N & $\bar{x}$ & s & t-waarde & p-waarde \\
\hline K2 & 7 & -2 & 11 & -0.42 & 0.6866 \\
H2 & 7 & -3 & 4 & -1.85 & 0.1140 \\
G2 & 6 & 11 & 25 & 0.98 & 0.3841 \\
\hline
\end{tabular}

egter nie statisties beduidend nie. Klein $n$-waardes maak moontlik die rekenkundige gemiddelde verskille ten opsigte van gedragsvaardighede statisties onbeduidend.

Om die metings se prakticse beduidendheid te bepaal (Cohen, 1977: 77), is die 'effek grootte d' bepaal. Vir prakticse betckenisvolheid word 'n d-waarde groter as 0.6 geneem. In Tabel 4 en 5 word die beduidendheid van die verskiltellings tussen die gemiddeldes binne groepe vir Kontrole Groepe Een en Twee aangetoon.

Geen statistics beduidende verskille kom in Tabelle 4 en 5 voor nie. Daar kan dus aanvaar word dat die statisties en prakties beduidende verskille wat by die eksperimentele groep voorkom maar nie by die kontrolegroepe nie, die gevolg van die opleidingskursusingreep is.

In Tabel 6 word die beduidendheid van die verskille tussen die voor- en nametings van die Eksperimentele Groep en Kontrolegroep 1 getoets.

Volgens Tabel 6 word hipoteses 1 (H1) en 2 (H2) aanvaar. Die procfpersone wat dic kursus deurloop het, se kennis en houdings verskil beduidend van die voor- en nametings van die proefpersone wat nie die kursus deurloop het nic. Die toepassing van 'n onafhanklike veranderlike (opleiding) het dus wel ' $n$ invloed gehad. Hipotese $3(\mathrm{H} 3)$ is egter nie aanvaarbaar nie. Alhoewel die Eksperimentele Groep se rekenkundige gemiddelde vir gedragsvaardighede $8 \%$ groter is as dic van Kontrolegroep 1, is dit nie statisties beduidend nie, monntlik as gevolg van die klein $n$-waarde.

Volgens die omegawaarde $\left(w^{2}\right.$ word gebruik wanneer twee onafhanklike groepe se gemiddeldes met mekaar vergelyk word) verklaar die toepassing van die onafhanklike veranderlike (opleiding) $47 \%$ van die totale variansie van die kursusgangers se kennis en $16 \%$ van die kursusgangers se houdings. Ten opsigte van die persentasie totale variansie wat deur opleiding verklaar word, kan dus net die kennisverbetering met 'n omegawaarde groter as $20 \%$ (Du Toit, 1985: 133), as praktics betckenisvol beskou word. In terme van die Bonferroni-aanpassing bly beide die kennis- en houdingsvraclys se resultate steeds statisties beduidend.

In Tabel 7 word die beduidendheid van die verskille tussen dic voor- en na-nametings van die Eksperimentele Groep en Kontrolegroep 1, drie maande later getoets, aangedui.

Volgens Tabel 7 word hipoteses 4 (H4) en 5 (H5) aanvaar. Dic verskillc tussen dic Eksperimentcle Groep en Kontrolegroep 1 se kennis- en houdingstellings is steeds beduidend. Hipoteses 6 (H6) en 7 (H7) word egter verwerp.

Tabel 6 Beduidendheid van die verskiltellings (voor- en nametings) tussen die Eksperimentele Groep en Kontrolegroep 1 (Hipoteses 1 en 3)

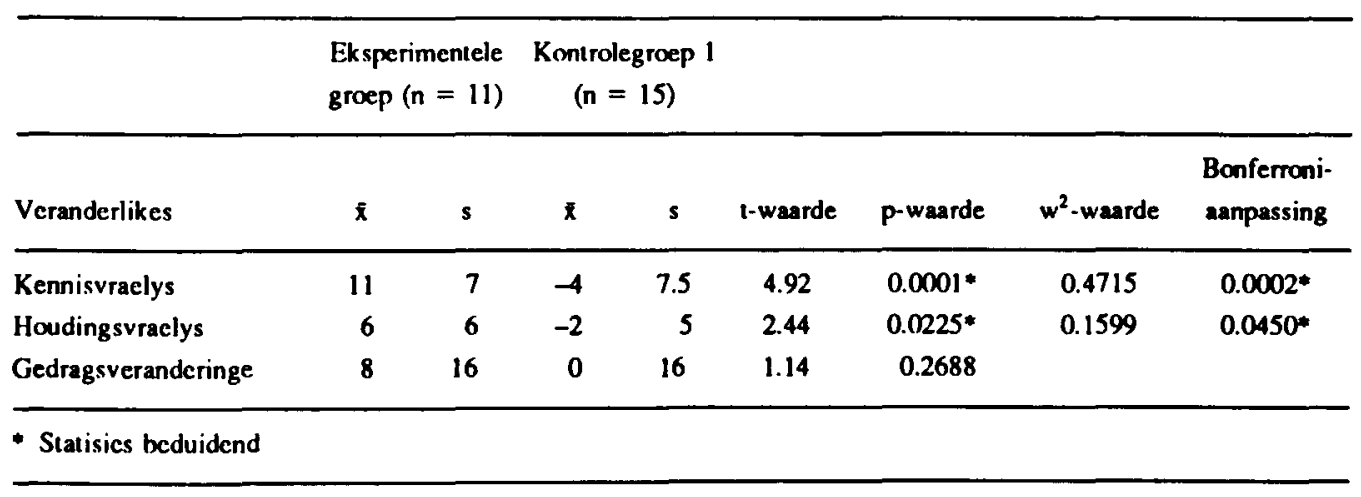


Tabel 7 Beduidendheid van die verskiltellings (voor- en na-na-metings) tussen die Eksperimentele groep en Kontrolegroep 1 (Hipoteses 4 tot 7 )

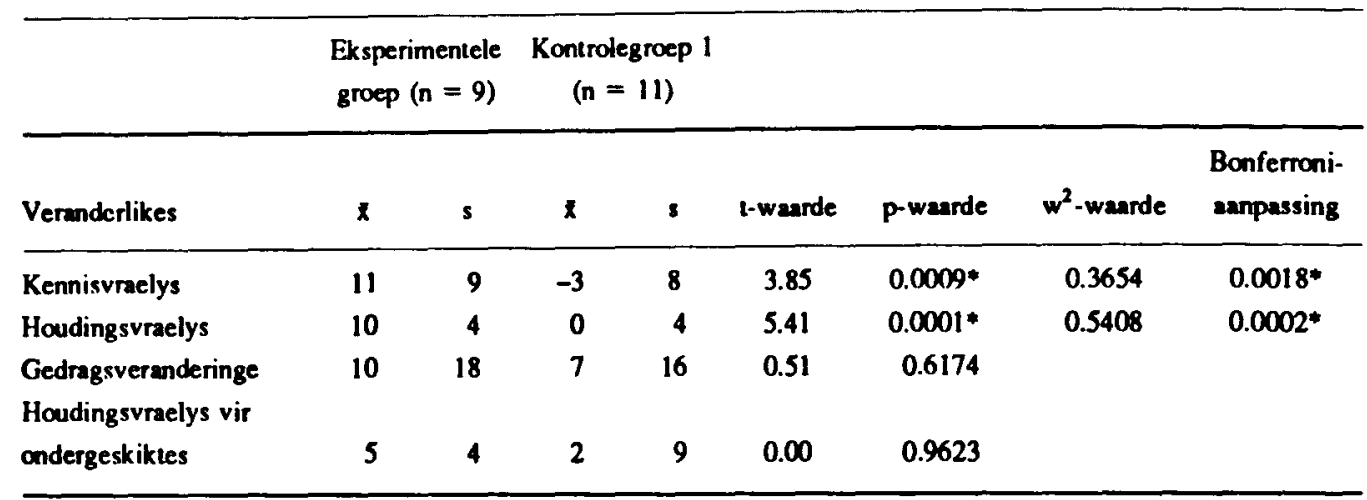

- Statisies beduidend

Die verskille tussen dic Eksperimentele Groep en Kontrolegroep 1 se gedragsvaardighcidstellings asook die ondergeskiktes se houdingstelling is dus nic beduidend nie.

Volgens dic omegawaarde verklaar dic wepassing van 'n onafhanklike veranderlike (opleiding) $36 \%$ van dic totalc variansie van die kursusgangers se kennis en $54 \%$ van die kursusgangers se houdings. Beide dic kennis- en houdingsvraelys se resultate bly statisties beduidend ten opsigte van die Bonferroni-aanpassing.

In Tabel 8 word die beduidendheid van die verskille tussen die na- en na-na-tellings van albei kontrole groepe, drie maande later getoets, aangedui. Die doel van die ontleding, ter ondersteuning van die hipoteses se resultate, is om die effek van toetsing oor 'n periode van drie maande tc bepaal.

Uit Tabel 8 is dit duidelik dat hier geen statisties beduidende verskille tussen Kontrolegroep 1 en 2 se na- en nanametings is nic. Dic herhaalde toetsing het dus geen beduidende invloed op die resultate gehad nic.

\section{Gevolgtrekkings en aanbevelings}

Die navorsing het dus gepoog om op 'n wetenskaplikgefundecrde wyse 'n bestuursverwante kursus te evalueer.

Die volgende dirckte afleidings kan gemaak word uit die metings wat voor dic aanvang van, dirck daarna en drie maande na afloop van dic kursus plaasgevind het:

- Die kursusgangers se kennis van bestuursbeginsels en -tegnicke het as gevolg van dic kursus dirck na dic kursus met $47 \%$ verbeter. Alhoewel 'n mate van kennisafname

Tabel 8 Beduidendheid van die verskiltellings (na- en na-nametings) tussen Kontrolegroep 1 en 2

\begin{tabular}{lcccccc}
\hline \multicolumn{5}{c}{$\begin{array}{c}\text { Kontrolegroep } \\
1(n=11)\end{array}$} & \multicolumn{2}{c}{$\begin{array}{c}\text { Kontrolegrop } \\
2(n=7)\end{array}$} \\
\hline Veranderlikes & 1 & $s$ & $\overline{1}$ & s & t-waarde & p-waarde \\
\hline $\begin{array}{l}\text { Kennisvraelys } \\
\text { Houdingsvrac- } \\
\text { lys }\end{array}$ & 1 & 3 & -2 & 11 & 0.84 & 0.4050 \\
$\begin{array}{l}\text { Gedragsveran- } \\
\text { deringe }\end{array}$ & -2 & 3 & -3 & 4 & 0.88 & 0.3890 \\
\hline
\end{tabular}

drie maande na die kursus gemeet is, is daar steeds 'n blywende $36 \%$ kennisverbetering drie maande na die kursus.

- Dic kursusgangers se houdingsingesteldheid teenoor bestuursbeginsels en -tegnicke het tot $16 \%$ direk na die kursus positicf toegeneem en tot $54 \%$ drie maande na die kursus.

- Die kursusgangers se gedragsvaardighede asook die effek daarvan op hulle ondergeskiktes is egter as onbeduidend gemeet.

- Die herhaaldelike gebruik van die meetinstrumente het geen beduidende effek op die resultate gehad nie.

Daar kan dus aanvaar word dat die kursus wel voldoen het aan sy doclwitte oor dic kort termyn (driemaandeperiodc) ten opsigte van kennis- en houdingsverbetering. Daar moet egter ook aanvaar word dat die kursus, moontlik as gevolg van verskcic cksterne faktore, nie aan sy doelwitte ten opsigte van verbeterde gedragsvaardighede en houdingsingesteldheid by ondergeskiktes oor dic kort termyn voldoen het nie.

Deur aandag aan spesificke opleidings- en ontwikkelingsintervensies (ontwikkcling van onder andere praktykgerigte gedragsvaardighede) te gee, is dit dalk wel moontlik om die kursus se tekortkominge (verdere bchoeftes) aan te spreek en dit terselfdertyd koste-effektief te hou.

Aangesien hierdie betrokke landboukoöperasie die grootste landboukoöperasie in die suidelike halfrond is, met oor die 100 bedryfspunte versprei oor ongeveer $30 \%$ van SuidAfrika se oppervlakte, kan hicrdie kooperasie as redelik verteenwoordigend van veral landboukoöperasies in die hoeveldstreek beskou word. Opvolgnavorsing by andersoortige landboukoöperasies is egter noodsaaklik voordat uitsluitsel or die problcem van eksterne geldigheid verkry sal kan word.

Vir toekomstige navorsing word benewens die uitbreiding na andersoortige koöperasies hierbo vermeld, ook aanbeveel dat die navorser meer motiverende persoonlike kontak tussen homself en die proefpersone mot bewerkstellig gedurende die navorsingstydperk (veral met die oog op verbeterde gedragsvaardighede) en dat die invloed van die opleidingskursus oor 'n langer tydperk as drie maande geevalucer moet word. 


\section{Verwysings}

Basson, P.A. 1987. Die relatiewe effektiwiteit van die tradisionele klaskamermetode en die bevoegdheidsgebaseerde benadering van opleiding op gedragsverandering. D.Com.proefskrif, Pretoria: Universiteit van Suid-Afrika.

Bell, J.D. \& Kerr, D.L. 1987. 'Measuring training results: key to management commitment', Training and Development Journal, Vol. 41, No. 1: 70-73.

Bimbraver, H. 1987. 'Evaluation techniques that work', Training and Development Journal, Vol 41, No. 7: 53-55.

Cohen. J. 1977. Statical power analysis for the behavioural sciences. New York, N.J.: Academic Press.

Deterline, W.A. 1977. 'Credibility in training: part V: what do we really want to know?', Training and Development Journal, Vol. 31, No. 4: 14-15.

Du Toit, J.M. 1985. Statistiese metodes. Stellenbosch: Kosmo.

Edwards, A.L. 1957. Techniques of attitude scale construction. New York : Appleton-Century-Crofts.

Flippo, E.B. 1981. Personnel management. Fifth edition. Auckland: McGraw-Hill.

Heunis. D.F. 1987. Die laak van die eerstevlaktoesighouer in die
Suid-Afrikaanse staatsdiens. M.A.-skripsie, Port Elizabeth: Universiteit van Port Elizabeth.

Jacobs, W. 1985. 'Toesighoueropleiding: waar staan ons?', Human Resource Management, Vol. 1, No. 1: 35-36, Mei.

Marais, F.S.S \& Vlok. M.A. 1981. Evalueringspraktyke. Johannesburg: BUO, Randse Afrikaanse Universiteit.

Myburgh, J. 1988. Die evaluering van ' $n$ kursus in arbeidsverhoudinge vir loesighouers by ' $n$ Suid-Afrikaanse landboukoöperasie. M.A.-skripsic, Potchefstroom: Potchefstroomse Universiteit vir Christelike Hoèr Onderwys.

Nonje, J.D. \& Crous, M.J. 1990. Die veranderde rol van bestuwr oor die volgende dekade - 'n kritiese beskouing. Bloemfontein: Universiteit van die Oranje-Vrystaat.

Schilbach, C. 1983. Die ontwikkeling van leierskapvaardighede by middelvlakbestuurders. D.Com.-proefskrif. Pretoria: Universiteit van Pretoria.

Strydom, W.A. 1993. Evaluering van 'n opleidingskursus in bestuursbeginsels en -tegnieke vir eerstelyntoesighouers by 'n Suid-Afrikaanse landboukoöperasie. M.A.-skripsie, Potchefstroom: Potchefstroomse Universiteit vir Christelike Hoèr Onderwys. 